\title{
Nota Editorial
}

\section{Nuevas Expectativas de Mejora a Pesar de las Dificultades}
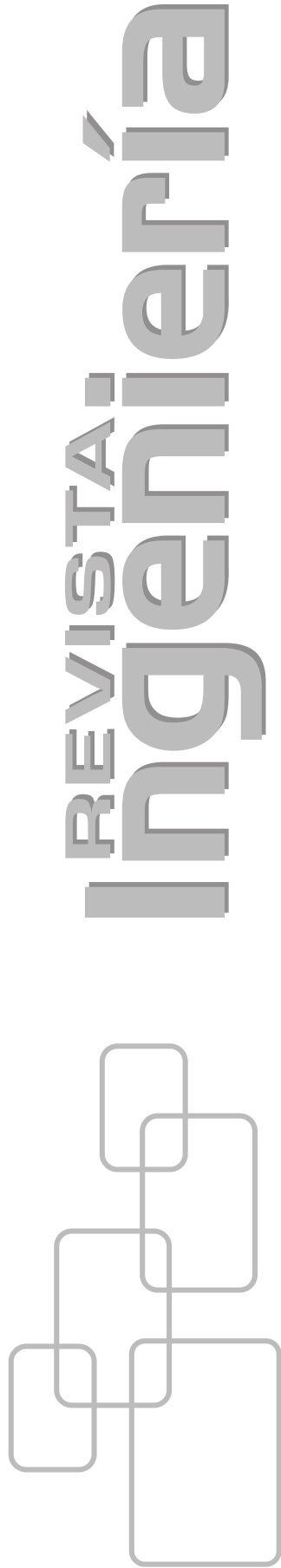

Open access

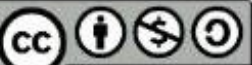

Un nuevo año y un nuevo volumen de la Revista Ingeniería. Este año está lleno de expectativas para el mejoramiento. Nuestro objetivo apunta a consolidarnos dentro de la base de revistas indexadas en Publindex, dejando atrás momentos difíciles; además, buscaremos mejorar el impacto y visualización de la revista implementando nuevas estrategias que nuestra comunidad irá conociendo con el pasar del año. Agradecemos que nuestras intenciones se hayan visto respaldadas por la comunidad científica, lo cual se evidencia en el volumen de contribuciones que han llegado en los últimos días.

Lamentablemente, y esto se ha salido de las manos de la dirección editorial, los procesos administrativos siempre van a un paso diferente al de los procesos académicos, por lo que generalmente no van más rápido para permitir una normal operación del trabajo científico. La parte administrativa tiende a retrasar y a entorpecer el desarrollo normal de los procesos de la revista. En esta oportunidad, la Revista Ingeniería se ha visto seriamente afectada por los retrasos administrativos en lo que tiene que ver con la contratación del equipo editorial, el cual es fundamental para asegurar el cumplimiento de los procesos editoriales definidos en procesos tan fundamentales como la verificación de requisitos, corrección de estilo y diagramación.

Lamentablemente, la Universidad solo reconoce la importancia de la revista cuando se alcanzan resultados positivos como lograr indexaciones. Sin embargo, los entes administrativos no reconocen que este es un proceso continuo que requiere de las garantías para seguir funcionando y que al no proporcionar las herramientas adecuadas para que la revista pueda cumplir con sus procesos, entre ellos la periodicidad, se afecta gravemente la posibilidad de mantenerla en los lugares de prestigio a los cuales ha logrado llegar.

Pedimos disculpas a nuestros autores que acuciosamente realizan sus procesos de postulación esperando que sean atendidos con diligencia por parte del equipo editorial, equipo que al menos durante los primeros dos meses del año no existió para dar trámite a sus contribuciones.

Esperamos que este inconveniente no se presente de nuevo y de nuestra parte nos comprometemos a incrementar esfuerzos para lograr lanzar las ediciones más rápidamente.

Cite this papes as: N. Diaz, "Nuevas Expectativas de Mejora a Pesar de las Dificultades.”, Ingeniería, Vol. 25, No.

1, pp. 4-5, Jan-Apr. 2020.

(C) The authors; reproduction right holder Universidad Distrital Francisco José de Caldas.

DOI: https://doi.org/10.14483/23448393.16029 
Esta edición presenta contribuciones en diferentes áreas de ingeniería, tocando aplicaciones basadas en sistemas difusos y soluciones para sistemas de almacenamiento híbridos en microrredes eléctricas, pasando por soluciones particulares de la industria petrolera y diseño conceptual de plantas para la industria de alimentos y finaliza con modelos de interacción para la reglamentación del uso de dispositivos móviles en el Congreso de la República.

Nelson Leonardo Diaz A., PhD.

Editor Revista INGENIERÍA

Universidad Distrital Francisco José de Caldas

nldiaza@udistrital.edu.co 